\title{
Comparison of visual acuity between phacoemulsification and extracapsular cataract extraction: a systematic review and meta- analysis
}

\author{
AiLing $\mathrm{Li}^{1 \#}$, Qiongmin $\mathrm{He}^{2 \#}$, Lijuan $\mathrm{Wei}^{3}$, Yingying Chen ${ }^{3}$, Shuxiong $\mathrm{He}^{2}$, Qiongkang Zhang ${ }^{2}$, Yijie Yan $^{3}$ \\ ${ }^{1}$ Ward I, Hainan Eye Hospital and Key Laboratory of Ophthalmology, Zhongshan Ophthalmic Center, Sun Yat-sen University, Haikou, China; \\ ${ }^{2}$ Department of Ophthalmology, Qionghai Jianping Hospital, Qionghai, China; ${ }^{3}$ Department of Ophthalmology, Hainan General Hospital (Hainan \\ Affiliated Hospital of Hainan Medical University), Haikou, China \\ Contributions: (I) Conception and design: A Li; (II) Administrative support: Y Yan; (III) Provision of study materials or patients: Q He; (IV) Collection \\ and assembly of data: L Wei; (V) Data analysis and interpretation: Y Chen; (VI) Manuscript writing: All authors; (VII) Final approval of manuscript: \\ All authors. \\ "These authors contributed equally to this work and should be considered as co-first authors. \\ Correspondence to: Yijie Yan. Department of Ophthalmology, Hainan General Hospital (Hainan Affiliated Hospital of Hainan Medical University), \\ Haikou 570311, China. Email: yanyijie11@163.com.
}

\begin{abstract}
Backgrounda Surgical treatment is the primary intervention for cataracts. Extracapsular cataract extraction (ECCE) is a routine surgery for cataracts, phacoemulsification (PE) is another procedure with a small incision and injury area. This study investigated the comparison of the effects of these two procedures on the patient's visual acuity.

Methods: Embase, PubMed, Cochrane Library, and SpringerLink databases were searched from January 2000 to August 2021 to obtain randomized controlled trial (RCT) studies of PE and ECCE procedures for cataract in English. After the initial screening, Revman 5.4 software was used for the meta-analysis.

Results: This meta-analysis included a total of eight articles with 1,015 affected eyes. The results showed that the rate of good final visual acuity in the PE group was higher than that in the ECCE group [odds ratio $(\mathrm{OR})=2.94,95 \%$ confidence interval $(\mathrm{CI}): 2.17-3.99, \mathrm{P}<0.00001]$, the incidence of vitreous Loss during PE surgery was lower than that in ECCE surgery ( $\mathrm{OR}=0.16,95 \% \mathrm{CI}$ : $0.04-0.64, \mathrm{P}=0.01$ ), as was the incidence of capsular tear ( $\mathrm{OR}=0.29,95 \% \mathrm{CI}: 0.10-0.85, \mathrm{P}=0.02)$, the incidence of capsule opacification after surgery $(\mathrm{OR}=0.20,95 \% \mathrm{CI}: 0.08-0.53, \mathrm{P}=0.001)$, and the incidence of cystoid macular edema after surgery $(\mathrm{OR}$ $=0.16,95 \%$ CI: $0.04-0.74, \mathrm{P}=0.02)$.
\end{abstract}

Discussion: Compared with ECCE, PE demonstrates an improvement in postoperative visual acuity and has fewer complications for cataract patients.

Keywords: Cataract; extracapsular cataract extraction (ECCE); phacoemulsification (PE); meta-analysis

Submitted Nov 23, 2021. Accepted for publication Dec 30, 2021.

doi: 10.21037/apm-21-3633

View this article at: https://dx.doi.org/10.21037/apm-21-3633

\section{Introduction}

Cataract is a common ophthalmic disease in individuals over 50 years of age. Patients acquire turbidity due to lens protein degeneration caused by natural aging, heredity, nutritional deficiency, immune and metabolic system abnormalities, trauma, poisoning, or radiation, resulting in decreased visual acuity and, in severe cases, blindness (1). Surgical procedures have become the primary treatment for cataracts, and intraocular lens (IOL) placement after cataract extraction can correct refractive errors and restore the patient's vision to a satisfactory state (2). Extracapsular 
cataract extraction (ECCE) is a routine surgery requiring suturing and a large incision (3). With the development of medical technology, phacoemulsification (PE) is now widely used and has become the treatment of choice for cataract in developed countries due to its short operation time, small incision and injury area, and rapid postoperative recovery (4). However, despite the advanced technology of $\mathrm{PE}$, the associated costs of the procedure are higher than ECCE, and its use in developing countries remains limited. Therefore, it remains meaningful to study the effect contrast between PE and ECCE (5,6). A meta-analysis by de Silva et al. in 2014 (7) included 11 randomized controlled trials (RCTs) with a total of 1,228 participants to compare the surgical effects of PE and ECCE. However, the studies included in their meta-analysis were mostly dated and of low quality, so their conclusions are of limited value. In this study, high-quality RCTs were included for meta-analysis to further investigate the comparison between PE and ECCE surgery. We present the following article in accordance with the PRISMA reporting checklist (available at https://apm. amegroups.com/article/view/10.21037/apm-21-3633/rc).

\section{Methods}

\section{Criteria for literature inclusion}

\section{Type of study}

Only RCTs published in English and with single or multicenter distributions were included. Case-control and cohort studies, case reports, controlled clinical trials (CCTs), or quasi-randomized studies were excluded.

\section{Participants}

All patients had cataracts caused by natural aging. Cataracts caused by trauma, poison, diabetes, and partial or complete subluxation of the lens were excluded, as were patients with vitreous in the current chamber.

\section{Intervention type}

The patients underwent PE or ECCE to remove the cataract, and posterior chamber IOL implantation was performed after the surgery. Included studies were required to report data comparing the two procedures (PE and ECCE). Studies that reported additional data concerning manual small-incision cataract surgery (MSICS) were included, but the additional data was excluded from the final analysis.

\section{Outcome indicators}

\section{Primary indicators}

Postoperative visual acuity: the proportion of patients who obtained good vision (as defined by visual acuity $>6 / 12$ ).

\section{Secondary indicators}

Intraoperative complications: the proportion of zonular dialysis, vitreous loss, capsular tear, or central corneal edema occurring during surgery.

Postoperative complications: the incidence of postoperative posterior capsule opacification, high astigmatism, or cystoid macular edema.

\section{Follow-up duration}

Studies reported the follow-up duration from one to 6 months were included.

\section{Search strategy and literature screening}

\section{Electronic retrieval}

Embase (January 2000 to August 2021), PubMed (January 2000 to August 2021), Cochrane Library (August 2021), and SpringerLink (January 2000 to August 2021) databases were searched for RCTs published after 2000 and in the English language.

\section{Keyword matching}

A keyword search was conducted with the following keywords: [phacoemulsification/PE] AND [extracapsular cataract extraction/ECCE] OR [cataract].

\section{Literature screening}

Two researchers independently conducted an initial screening of the identified studies by reading the titles and abstracts. Duplicate and unqualified studies were excluded. If the two researchers had a different opinion regarding any study, a third researcher was consulted for discussion until consensus was reached.

\section{Data extraction}

Two researchers independently extracted the data and read the full text of each article. Any missing information was obtained by contacting the corresponding author in the original study. The extracted information was recorded in an Excel spreadsheet. After completion, a cross-check 
was performed of the two researchers' records, and any inconsistencies were discussed and finalized. The extracted contents included:

(I) Basic information of the study: title, author, mailing address, name of publication, and publication date;

(II) Basic characteristics of the study: inclusion and exclusion criteria, total sample size, number of groups, and number of samples in each group;

(III) Basic characteristics of the participants: age, gender ratio, and duration of illness;

(IV) Characteristics of the interventions: the different intervention methods used in different groups and the follow-up time;

(V) Outcome indicators: the number of cases of visual acuity improvement before and after surgery, and type and proportion of complications.

\section{Literature bias and evaluation analysis}

The risk of bias for the RCT studies was assessed according to the Cochrane Handbook for Systematic Reviews of Interventions and expressed as high, low, or unclear. We classified the literature according to class A, B and C. Class A: all of the 6 aspects, including random method, distribution concealment, blind method, data integrity, selective reporting and other bias were well implemented. Class B: any one or more aspect partially met the criteria. Class C: any one or more of them were not well implemented.

\section{Statistical analysis}

The odds ratio (OR) and 95\% confidence interval (CI) were used to evaluate dichotomous variables (rate of good postoperative visual acuity, proportion of intraoperative complications, and proportion of postoperative complications), and the forest plot was used to display the results.

\section{Integrity and consistency of analysis}

For patients with only one eye diseased, we assigned them to the different surgery types; for patients with two eyes diseased, the study needed to specify whether both eyes were assigned to the same group at the same time. We made every effort to avoid the situation where two eyes from one individual were assigned to different surgical methods.

\section{Handling of data loss}

Cases lost to follow-up were required to be described in detail in the studies, and should be counted during the analysis.

\section{Heterogeneity assessment}

The $\mathrm{I}^{2}$ statistic and Q test were used to assess heterogeneity. An $\mathrm{I}^{2}$ value $>50 \%$ or a $\mathrm{P}$ value $<0.1$ indicated statistically significant heterogeneity.

\section{Publication bias analysis}

Funnel plots were used to represent publication bias.

\section{Data synthesis}

RevMan 5.4 software (Cochrane Collaboration) was used as the analysis tool for this study.

\section{Heterogeneity survey}

Heterogeneity was investigated using subgroup analysis.

\section{Sensitivity analysis}

For analyses without significant heterogeneity, fixed-effects and random-effects models were used. If there was no significant difference, we considered that the sensitivity was good.

\section{Results}

\section{Literature search results and screening process}

Figure 1 shows the results of the literature search and the screening process.

\section{Basic characteristics of the included studies}

Eight RCTs were included in our study, with a total of 1,015 affected eyes. The youngest patient was 49 years old, and the oldest was 92 years old. The grouped sample sizes ranged from 33 to 146 . The studies were conducted in several countries, including Greece, Brazil, Malaysia, China, Kashmir, Pakistan, and Nigeria. The basic characteristics of the studies are shown in Table 1.

\section{Assessment of risk of bias}

We used the Cochrane Handbook for Systematic Reviews of Interventions to evaluate the studies included in this meta-analysis. All studies described the method of random sequence grouping. Except for one study (8), all other studies described the allocation concealment method and only one study (9) failed to mention the blinding method. 


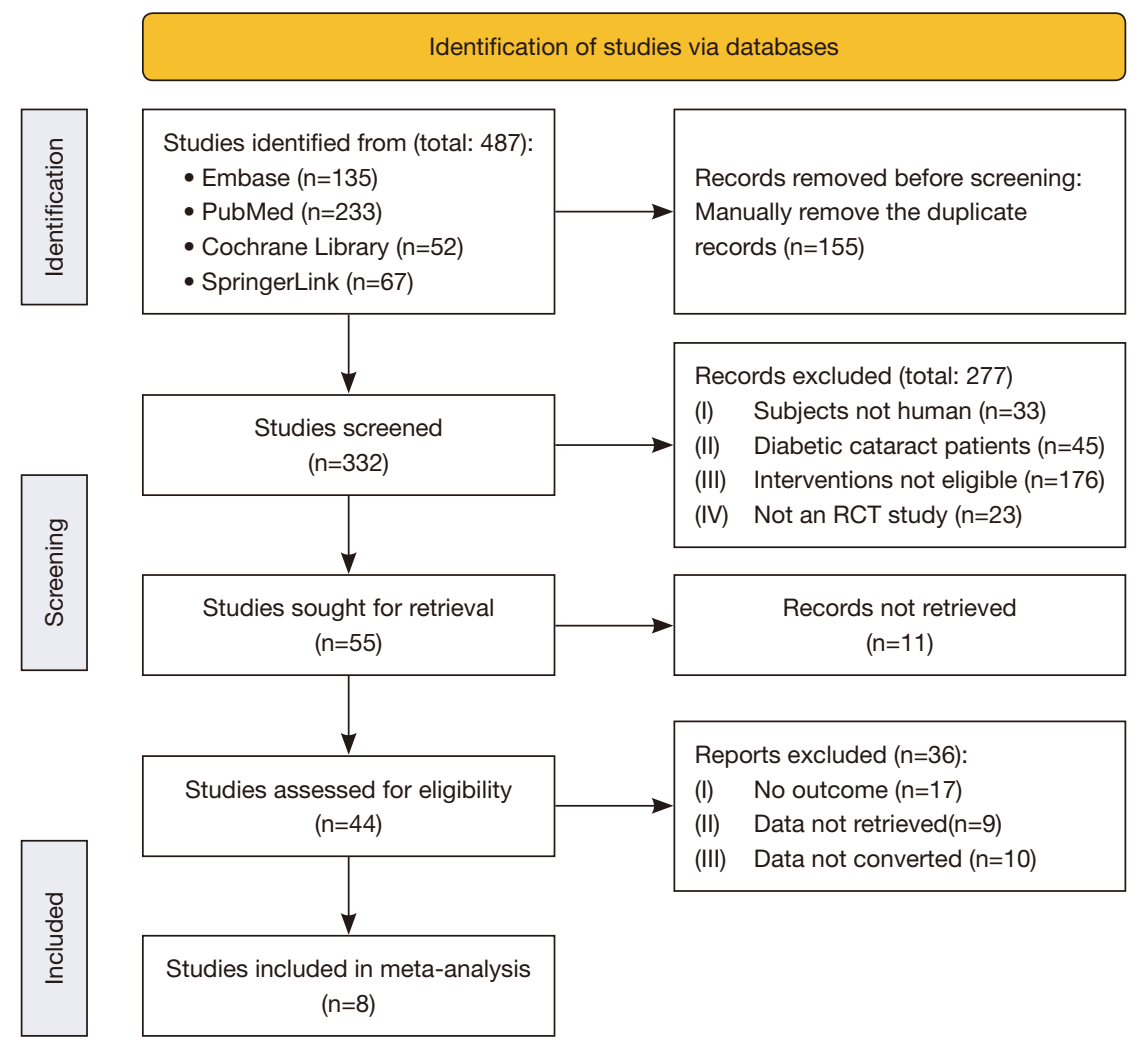

Figure 1 Literature screening flow chart.

All studies detailed dropout cases. No selective reporting or other biases were found, as shown in Table 2.

\section{Intervention effect}

\section{Visual acuity outcome}

All studies described the proportion of best-corrected visual acuity. The rate of good vision was defined as corrected visual acuity at $6 / 6$ or above. Of the total number of eyes, 445 were included in the PE group, and 219 were included in the ECCE group. The results showed that the rate of good final visual acuity in the PE group was higher than that in the ECCE group (OR =2.94, 95\% CI: 2.17-3.99, $\mathrm{P}<0.00001)$. There was no significant heterogeneity between the studies $\left(\mathrm{I}^{2}=17 \%, \mathrm{P}=0.30\right)$, as shown in Figure 2 .

The eight studies were further divided into four subgroups according to their geographical region: Europe, Asia, Africa, and America. The results showed that there was no statistically significant heterogeneity among the internal subgroups. The rate of good vision in the PE group was higher than that in the ECCE group, indicating that the results were not related to race or regional distribution.

\section{Intraoperative complications}

The results of the main intraoperative complications are listed in Table 3. The proportion of vitreous prolapse and capsular tear in PE surgery was lower than that in ECCE surgery. There was no significant difference in the proportion of other complications, such as zonular dialysis and central corneal edema.

\section{Postoperative complications}

Table 4 lists the results of the main postoperative complications. The proportion of capsule opacification and cystoid macular edema after PE surgery was lower than that after ECCE surgery, and there was no significant difference in the proportion of other complications such as high astigmatism.

\section{Sensitivity analysis}

For the analysis in Figure 2, a random-effects model was used $(\mathrm{OR}=2.98,95 \% \mathrm{CI}: 2.12-4.17, \mathrm{P}<0.00001)$, which did not differ significantly from the results of the fixedeffects model, so the stability of the analysis was judged as good. 
Table 1 Basic study information, patient characteristics, surgical method, follow-up period, and outcome indicators

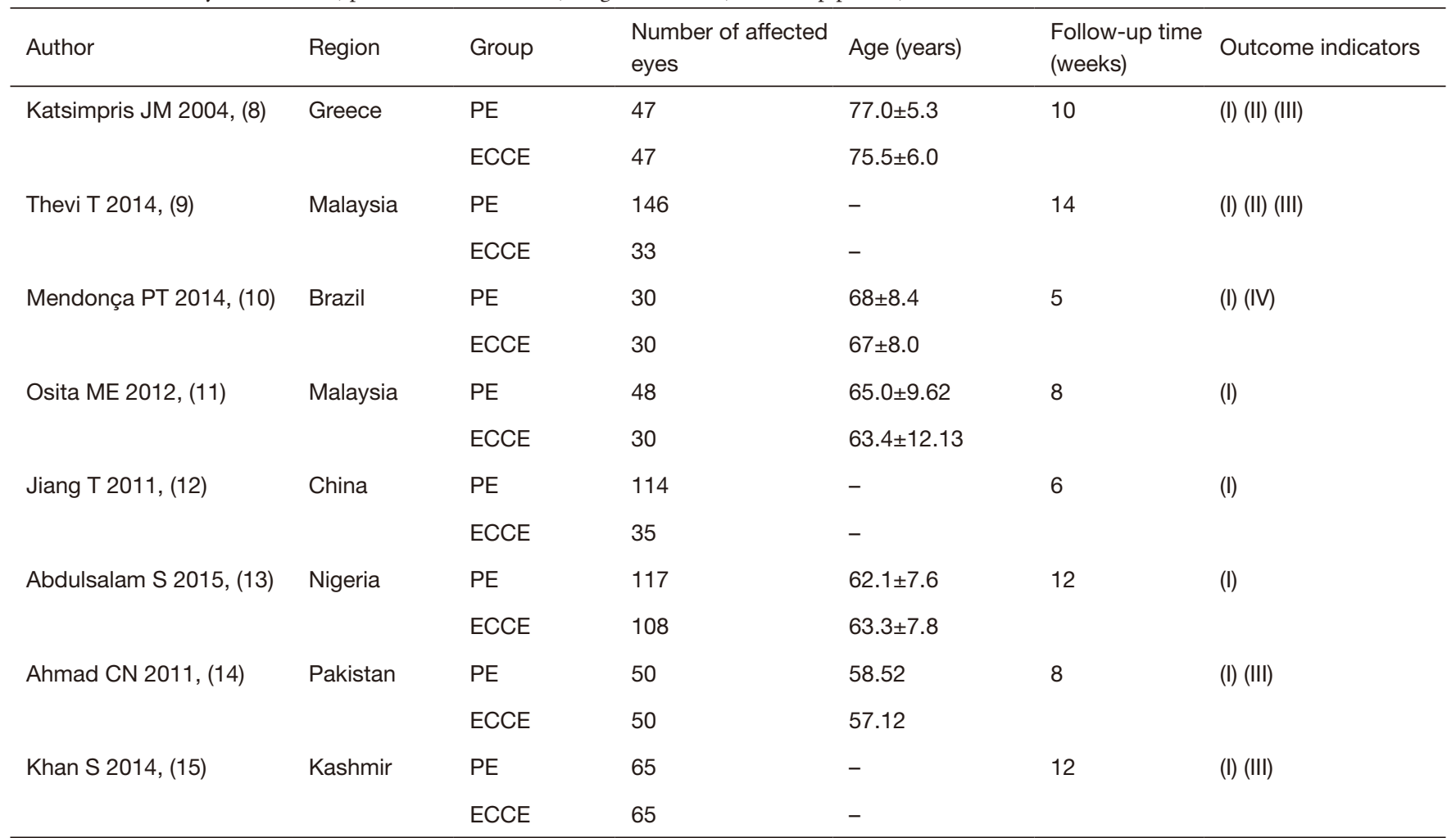

Outcome indicators: (I) best-corrected visual acuity; (II) intraoperative complications; (III) postoperative complications; (IV) quality of life.

PE, phacoemulsification; ECCE, extracapsular extraction.

Table 2 Risk of bias and quality assessment based on the Cochrane Handbook for Systematic Reviews of Interventions

\begin{tabular}{|c|c|c|c|c|c|c|c|}
\hline Study & $\begin{array}{l}\text { Random sequence } \\
\text { generation }\end{array}$ & $\begin{array}{l}\text { Classification } \\
\text { hiding }\end{array}$ & $\begin{array}{l}\text { Blind } \\
\text { method }\end{array}$ & $\begin{array}{c}\text { Data } \\
\text { integrity }\end{array}$ & $\begin{array}{l}\text { Optional } \\
\text { reporting }\end{array}$ & $\begin{array}{l}\text { Other } \\
\text { Bias }\end{array}$ & Class \\
\hline Katsimpris JM 2004, (8) & Low & Unclear & Low & Low & Low & Low & $\mathrm{B}$ \\
\hline Thevi T 2014, (9) & Low & Low & Unclear & Low & Low & Low & B \\
\hline Mendonça PT 2014, (10) & Low & Low & Low & Low & Low & Low & $A$ \\
\hline Abdulsalam S 2015, (13) & Low & Low & Low & Low & Low & Low & A \\
\hline Ahmad CN 2011, (14) & Low & Low & Low & Low & Low & Low & A \\
\hline Khan S 2014, (15) & Low & Low & Low & Low & Low & Low & $A$ \\
\hline
\end{tabular}

\section{Analysis of publication bias}

As shown in Figure 3, the funnel plot indicated that the distribution of the eight articles was basically symmetrical without significant publication bias.

\section{Discussion}

\section{Summary of study results}

Since Dr. Kelman's 1967 invention of the PE technique 


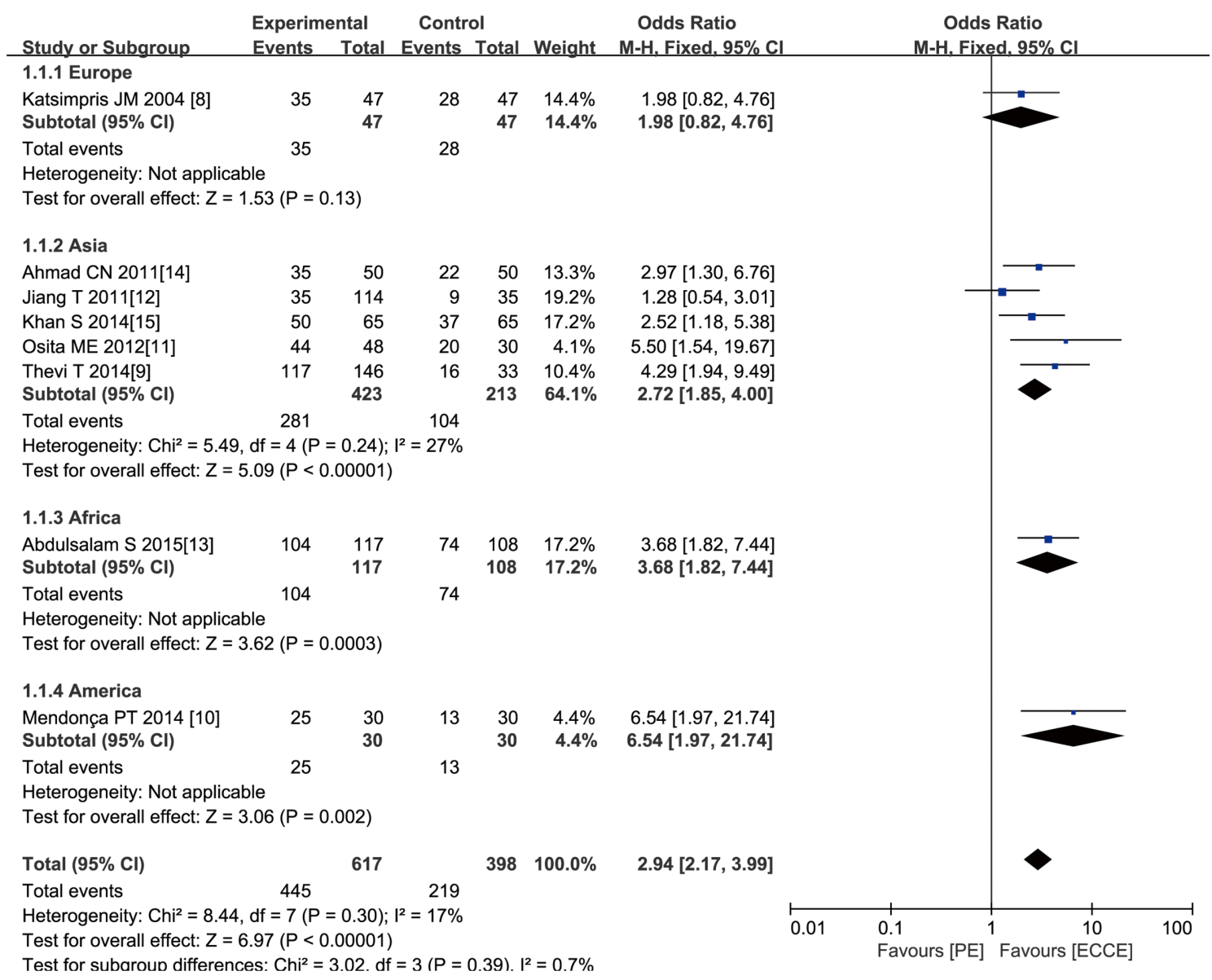

Figure 2 Comparison of good visual acuity rate in the ECCE and PE groups. ECCE, extracapsular cataract extraction; PE, phacoemulsification; M-H, Mantel-Haenszel; CI, confidence interval.

Table 3 Comparison of intraoperative complications

\begin{tabular}{llllll}
\hline Complications & Eyes & Study num & Statistical method & Effect estimate & P value \\
\hline Zonular dialysis & 273 & 2 & Odds ratio $(\mathrm{M}-\mathrm{H}$, random, 95\% Cl) & $0.17(0.01-2.54)$ & 0.20 \\
Vitreous loss & 273 & 2 & Odds ratio $(\mathrm{M}-\mathrm{H}$, fixed, 95\% Cl) & $0.16(0.04-0.64)$ & 0.01 \\
Capsular tear & 403 & 3 & Odds ratio $(\mathrm{M}-\mathrm{H}$, fixed, 95\% Cl) & $0.29(0.10-0.85)$ & 0.02 \\
Central corneal edema & 273 & 2 & Odds ratio $(\mathrm{M}-\mathrm{H}$, random, 95\% Cl) & $0.34(0.02-4.79)$ & 0.42 \\
\hline
\end{tabular}

$\mathrm{M}-\mathrm{H}$, Mantel-Haenszel test; $\mathrm{Cl}$, confidence interval.

in the United States, it has undergone many years of improvement and development in clinical practice. It is now a universally well-recognized and advanced surgical method. The procedure involves placing a probe into the eye chamber through a small incision, breaking the turbid lens into chyle and suctioning it out, and then implanting the IOL to allow the patient to regain visual acuity $(16,17)$.
PE surgery is characterized by a small incision and a short operation time. A previous study (12) recorded the operation time of PE and found that surgery was completed within 15 minutes for $53.5 \%$ of patients and within 30 minutes for $95.6 \%$ of patients, indicating that surgery was completed within 30 minutes for most patients. Since PE surgery has better control, postoperative visual acuity recovery is better. 
Table 4 Comparison of postoperative complications

\begin{tabular}{llllll}
\hline Factors & $\begin{array}{l}\text { Number of } \\
\text { participating patients }\end{array}$ & $\begin{array}{l}\text { Number } \\
\text { of studies }\end{array}$ & Statistical method & Effect estimate & P value \\
\hline Posterior capsule opacification & 403 & 3 & Odds ratio $(\mathrm{M}-\mathrm{H}$, fixed, 95\% Cl) & $0.20(0.08-0.53)$ & 0.001 \\
High astigmatism & 273 & 2 & Odds ratio $(\mathrm{M}-\mathrm{H}$, fixed, 95\% Cl) & $0.29(0.05-1.85)$ & 0.19 \\
Cystoid macular edema & 273 & 2 & Odds ratio $(\mathrm{M}-\mathrm{H}$, fixed, 95\% Cl) & $0.16(0.04-0.74)$ & 0.02 \\
\hline
\end{tabular}

$\mathrm{M}-\mathrm{H}$, Mantel-Haenszel test; $\mathrm{Cl}$, confidence interval.

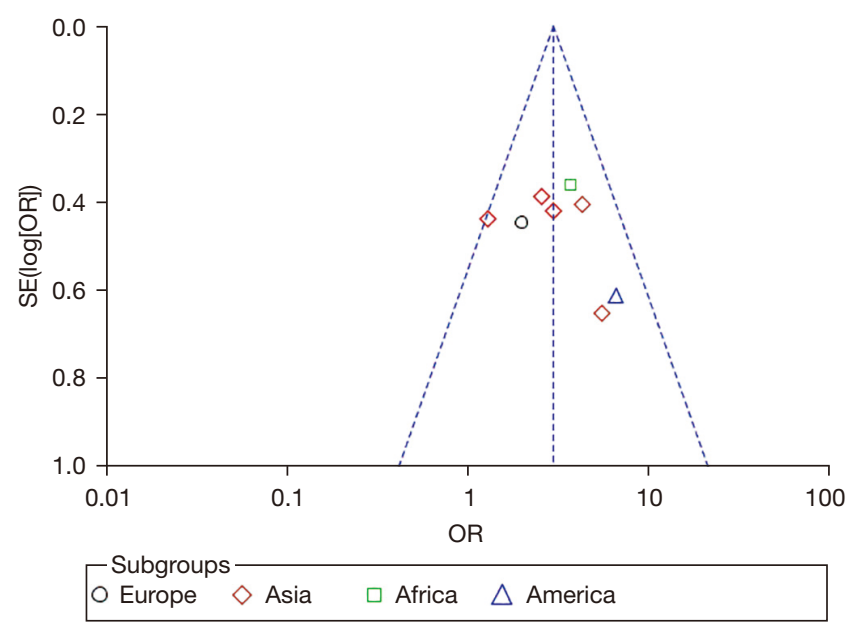

Figure 3 Funnel plot analysis. OR, odds ratio; SE, standard error.

In the present meta-analysis, a total of 1,015 affected eyes in eight articles were included, and those with corrected visual acuity of $6 / 6$ or more were considered to have good visual acuity correction. The meta-analysis results showed that PE surgery had better visual acuity compared with ECCE surgery. The study also compared intraoperative and postoperative complications. The proportion of complications, such as vitreous prolapse, capsule tear, capsule opacification, and cystoid macular edema during and after PE, was lower than that of ECCE, suggesting that $\mathrm{PE}$ had fewer complications.

\section{Comparison with other studies}

The results of de Silva et al. (7) showed that compared with ECCE surgery, PE surgery had a lower incidence of complications and better postoperative visual acuity, consistent with the present study results.

Moulick et al. (18) compared possible complications of posterior capsular opacification in PE, ECCE, and MSICS and showed that the incidence of posterior capsular opacification was lower in the PE and MSICS procedures than in ECCE, which was also consistent with the results of this study.

In this study, because only a few articles reported the incidence of ocular hypertension, these results were not included in the analysis. However, a previous study (8) reported that the incidence of early postoperative ocular hypertension after PE surgery was $8.4 \%$, in contrast to $29.8 \%$ after ECCE surgery. This significantly smaller incidence of ocular hypertension after PE compared with ECCE is consistent with the results of Pal et al. (19).

Although the intraoperative and postoperative complications of PE surgery are less than those of ECCE surgery, there were still a small number of complications happened, such as posterior capsule opacification, elevated intraocular pressure, corneal edema and retinal detachment. Posterior capsule opacification can be corrected by laser. Elevated intraocular pressure is a common phenomenon after surgery and generally recovers itself. The probability of corneal edema and retinal detachment is low and can also be corrected by surgery. Therefore, the safety of $\mathrm{PE}$ operation is good (20).

Nevertheless, despite the technical advantages of the $\mathrm{PE}$ procedure over other procedures, its cost is higher. In a study conducted by Kara et al. (21), the mean operative cost for 101 patients who received PE surgery was US\$587.71, while the mean operative cost for 104 patients who received ECCE surgery was US\$341.21. Hence the ECCE procedure is still preferred in low-income populations.

\section{Quality of evidence and possible bias}

In this study, the random sequence generation and blinding methods were described in detail. Only one study failed to mention the allocation concealment method (8), and another did not report the blinding method (9). All of the RCTs provided detailed descriptions of the dropout cases during follow-up. Therefore, the risk of bias in the 
literature was small, and the sensitivity analysis showed that the results were stable. The publication bias analysis showed that there was no significant publication bias. However, a limitation of the present study was that too few studies included details of complications, which compromised the quality of this evidence. The comparison of complications between the two surgical methods requires further investigation.

\section{Conclusions}

In summary, $\mathrm{PE}$ cataract extraction shows better postoperative visual acuity improvement and fewer complications than ECCE. Since the cost of surgery was not analyzed in this study, this topic will require further exploration by using more high-quality RCT studies in clinical practice.

\section{Acknowledgments}

Funding: This project was supported by Hainan Province Clinical Medical Center.

\section{Footnote}

Reporting Checklist: The authors have completed the PRISMA reporting checklist. Available at https://apm. amegroups.com/article/view/10.21037/apm-21-3633/rc

Conflicts of Interest: All authors have completed the ICMJE uniform disclosure form (available at https://apm. amegroups.com/article/view/10.21037/apm-21-3633/coif). The authors have no conflicts of interest to declare.

Ethical Statement: The authors are accountable for all aspects of the work in ensuring that questions related to the accuracy or integrity of any part of the work are appropriately investigated and resolved.

Open Access Statement: This is an Open Access article distributed in accordance with the Creative Commons Attribution-NonCommercial-NoDerivs 4.0 International License (CC BY-NC-ND 4.0), which permits the noncommercial replication and distribution of the article with the strict proviso that no changes or edits are made and the original work is properly cited (including links to both the formal publication through the relevant DOI and the license). See: https://creativecommons.org/licenses/by-nc-nd/4.0/.

\section{References}

1. Chatterjee S, Agrawal D, Parchand SM, et al. Visual outcome and prognostic factors in cataract surgery in ocular tuberculosis. Indian J Ophthalmol 2020;68:1894-900.

2. Ang M, Evans JR, Mehta JS. Manual small incision cataract surgery (MSICS) with posterior chamber intraocular lens versus extracapsular cataract extraction (ECCE) with posterior chamber intraocular lens for age-related cataract. Cochrane Database Syst Rev 2014;(11):CD008811.

3. Rajkarnikar S, Shrestha DB, Dhakal S, et al. Comparative Study of Extra Capsular Cataract Extraction (ECCE) and Small Incision Cataract Surgery (SICS): Experience on Cataract Surgery in a Tertiary Center of Army Hospital, Kathmandu. Nepal J Ophthalmol 2018;10:162-7.

4. Fesharaki H, Peyman A, Rowshandel M, et al. A comparative study of complications of cataract surgery with phacoemulsification in eyes with high and normal axial length. Adv Biomed Res 2012;1:67.

5. Toyama T, Ueta T, Yoshitani M, et al. Visual acuity improvement after phacoemulsification cataract surgery in patients aged $\geq 90$ years. BMC Ophthalmol 2018;18:280.

6. Briszi A, Prahs P, Hillenkamp J, et al. Complication rate and risk factors for intraoperative complications in resident-performed phacoemulsification surgery. Graefes Arch Clin Exp Ophthalmol 2012;250:1315-20.

7. de Silva SR, Riaz Y, Evans JR. Phacoemulsification with posterior chamber intraocular lens versus extracapsular cataract extraction (ECCE) with posterior chamber intraocular lens for age-related cataract. Cochrane Database Syst Rev 2014;(1):CD008812.

8. Katsimpris JM, Petropoulos IK, Apostolakis K, et al. Comparing phacoemulsification and extracapsular cataract extraction in eyes with pseudoexfoliation syndrome, small pupil, and phacodonesis. Klin Monbl Augenheilkd 2004;221:328-33.

9. Thevi T, Reddy SC, Shantakumar C. Outcome of phacoemulsification and extracapsular cataract extraction: A study in a district hospital in Malaysia. Malays Fam Physician 2014;9:41-7.

10. Mendonça PT, Mendonça LT, Rosa AA, et al. Life quality assessment of patients after phacoemulsification or extracapsular cataract extraction. Arq Bras Oftalmol 2014;77:12-6.

11. Osita ME, Yuen SZ. The Outcome of Extracapsular and Phacoemulsification Cataract Extractions. Journal of Medicine and Biomedical Research 2012;11:123-8.

12. Jiang T, Jiang J, Zhou $Y$, et al. Cataract surgery in 
aged patients: phacoemulsification or small-incision extracapsular cataract surgery. Int J Ophthalmol 2011;4:513-8.

13. Abdulsalam S. Comparison of visual outcome between conventional extracapsular cataract extraction and phacoemulsification cataract surgery. J Health Res Rev 2015;2:99-102.

14. Ahmad CN, Yousif A, Siddique MZ, et al. Comparison of Visual Outcome after phacoemulsification versus extracapsular cataract extraction. Annals of King Edward Medical University 2011;17:251.

15. Khan S, Mir MD, Jehan A, et al. Clinical outcome of cataract extraction by extra capsular cataract extraction and phacoemulsificatio in government medical college, srinagar, kashmir, india. International Journal of Recent Scientific Research 2014;5;605-10.

16. Foster GJL, Allen QB, Ayres BD, et al. Phacoemulsification of the rock-hard dense nuclear cataract: Options and recommendations. J Cataract Refract Surg 2018;44:905-16.

17. He L, Cui Y, Tang X, et al. Changes in visual function

Cite this article as: $\mathrm{Li} \mathrm{A,} \mathrm{He} \mathrm{Q,} \mathrm{Wei} \mathrm{L,} \mathrm{Chen} \mathrm{Y,} \mathrm{He} \mathrm{S,}$ Zhang Q, Yan Y. Comparison of visual acuity between phacoemulsification and extracapsular cataract extraction: a systematic review and meta-analysis. Ann Palliat Med 2022;11(2):551-559. doi: 10.21037/apm-21-3633 and quality of life in patients with senile cataract following phacoemulsification. Ann Palliat Med 2020;9:3802-9.

18. Moulick PS, Rodrigues F, Shyamsundar K. Evaluation of Posterior Capsular Opacification following Phacoemulsification, Extracapsular and Small Incision Cataract Surgery. Med J Armed Forces India 2009;65:225-8.

19. Pal VK, Agrawal A, Suman S, et al. Long-term change in intraocular pressure after extracapsular cataract extraction with posterior chamber intraocular lens implantation versus phacoemulsification with posterior chamber intraocular lens implantation in Indians. Middle East Afr J Ophthalmol 2013;20:332-5.

20. Pershing S, Kumar A. Phacoemulsification versus extracapsular cataract extraction: where do we stand? Curr Opin Ophthalmol 2011;22:37-42.

21. Kara N Jr, Sirtoli MG, Santhiago MR, et al. Phacoemulsification versus extracapsular extraction: governmental costs. Clinics (Sao Paulo) 2010;65:357-61.

(English Language Editor: D. Fitzgerald) 